\title{
Low Back Pain and Associated Factors among Italian Equestrian Athletes: a Cross-Sectional Study
}

\author{
M. Ferrante ${ }^{1}$, F. Bonetti ${ }^{2}$, F. M. Quattrini ${ }^{3}$, M. Mezzetti ${ }^{4}$, S. Demarie ${ }^{5}$ \\ ${ }^{1}$ Foro Italico University Foundation, Rome, Italy \\ ${ }^{2}$ Department of Clinical Sciences and Translational Medicine, Tor Vergata University, Rome, Italy \\ ${ }^{3}$ Medical Department of Italian Equestrian Sport Federation, Rome, Italy \\ ${ }^{4}$ Department of Economics and Finance, Tor Vergata University, Rome, Italy \\ ${ }^{5}$ Department of Movement, Human and Health Sciences, University of Rome Foro Italico, Rome, Italy
}

\section{CORRESPONDING AUTHOR:}

\section{Mario Ferrante}

Foro Italico University Foundation

piazza Lauro De Bosis 15

00135 Rome, Italy

E-mail: info@mferrante.it

\section{DOI:}

10.32098/mltj.02.2021.19

LEVEL OF EVIDENCE: 4

\begin{abstract}
SUMMARY
Background. Low back pain (LBP) is a widespread condition in sport; it can lead to high treatment costs, dropping out of training and competition, decreased quality of life, and limitations to performance. Moreover, a large number of sport athletes suffer from chronic low back pain (CLBP). Among equestrian athletes low back pain is accepted as a symptom immanent to the sport.

Methods. The study is a cross-sectional survey conducted using an online cloud-based software among competitive Athletes members of the Italian Equestrian Sport Federation older than 18 years old $(\mathrm{n}=40932)$.

Results. 886 athletes participated in the survey: $21.90 \%$ were male and $78.10 \%$ were female.

LBP had a prevalence of $91.6 \%$ and $74.2 \%$ for life-time and 1 -year respectively, while CLBP had a prevalence of $23.9 \%$.

Prevalence of LBP is 61\% in Show-jumping, 13.6\% in Dressage, 6.3\% in Eventing, $2.9 \%$ in Horse Country Riding and 2.2\% in Reining.

Weight has a positive association with LBP (O.R. $1.0595 \%$ CI $=[1.02,1.09] \mathrm{p}$ $<0.05$ ), while age has a negative association (O.R. $0.9595 \% \mathrm{CI}=[0.94,0.98]$ $\mathrm{p}<0.05)$.

Practicing activity more than 5-6 hours a week has a positive association with CLBP (O.R. $1.2195 \% \mathrm{CI}=[1.05,1.4] \mathrm{p}<0.05)$. CLBP is associated with interrupted activity $(\mathrm{p}<0.001)$, drugs consumption $(\mathrm{p}<0.001)$ and restriction in participation $(\mathrm{p}<0.001)$. Conclusions. LBP and CLBP are very common conditions in equestrian athletes and their prevalence is higher compared to general population. LBP is more frequent in show-jumping compared to other disciplines. Age and weight are associated with lifetime LBP, with, respectively, a negative and positive association. Athletes with CLBP showed more disability in activities of daily living (ADLs) and tendency to suspend sports more frequently.
\end{abstract}

\section{KEY WORDS}

Chronic low back pain; dressage; eventing; horse-rider; lumbar spine; prevalence study; show jumping.

\section{INTRODUCTION}

LBP is defined as pain and discomfort, localized below the costal margin and above the inferior gluteal folds, with or without referred leg pain. LBP is considered chronic if it is present for most of the days in the previous 3 months (1).
The relationship between low back pain (LBP) and physical activity has been largely investigated and the role of physical activity in the treatment of low back pain is generally accepted $(1,2)$.

However, physical activity has been suggested to be both a preventive factor and a possible risk factor for LBP (3). 
There is, furthermore, evidence of an association between high physical work-loads and back injury (4). LBP is a widespread condition in sport as for the general population and, as reported in literature, lifetime prevalence in athletes ranges from 1 to $94 \%(5,6)$. As for the general population, LBP in athletes can lead to high treatment costs, dropping out of training and competition, decreased quality of life, and limitations to performance $(6,7)$. In this context, LBP is a relevant topic for sports medicine professionals as well as for athletes, coaches, and physiotherapists (6). Moreover, a large number of sport athletes suffer from chronic low back pain (CLBP) (8). According to published data, equestrian athletes have a significantly higher incidence of LBP compared to the general population, and this is generally accepted as a physiological consequence of sport (9).

A previous study reported that the highest forces during riding are absorbed through the rider's ischial tuberosities, pelvis, sacrum, and lumbar spine. That could contribute to the development of LBP (10). In addition, using an inappropriate saddle can be a risk factor for LBP (10, 11). However, in 3 equestrian disciplines (dressage, show jumping and vaulting) significant correlation between the intensity of riding or the riding discipline and frequency or severity of back pain was not observed. (9) This data has been confirmed in another study on a small group of elite riders (12). To the best of our knowledge no data was available for the Italian rider population.

The purpose of this study is to investigate, through a self-reported questionnaire, the prevalence of LBP among Italian equestrian athletes; which disciplines in equestrian sports are associated with a higher prevalence of LBP; how the training and competition levels affect the prevalence.

Furthermore, we investigate the prevalence of the CLBP and the correlation between training and equestrian disciplines. This information would facilitate identification of associated factors and the development of preventive strategies in special-risk sport groups.

\section{MATERIALS AND METHODS}

\section{Study design, setting and participants}

A cross-sectional survey among athletes members of the Italian National Equestrian Federation (FISE) was conducted from $1^{\text {st }}$ November 2018 to $31^{\text {st }}$ January 2019.

The study conforms to the Reporting of OBservational Studies in Epidemiology (STROBE statement) for reporting cross-sectional studies and to the Checklist for Reporting Results of Internet E-Surveys (CHERRIES).
All the athletes were asked to complete an online questionnaire on LBP through SurveyMonkey website (13). To complete the questionnaire all the participants had to accept the consent form describing purposes and procedures of the study and privacy policy. Athletes were informed about the survey through the official (FISE) website and the related social network pages, such as Facebook, Instagram, and WhatsApp. Furthermore, equestrian centers were informed through email sent by FISE.

Exclusion criteria were the presence of neurological disease, thus, paralympic riders were excluded.

All the athletes aged 18 or more, members of the FISE, were invited to answer the questionnaire.

According to the FISE database there were 40932 athletes eligible for the questionnaire, $37.68 \%$ were male and $62.32 \%$ female. $20704(50.58 \%)$ were competitive athletes (8192 males, 12512 females).

$20228(49.42 \%)$ were recreational athletes ( 7232 males, 12996 females). The minimum sample size to reach was 655 ; it was calculated with a confidence level of $99 \%$ and a confidence interval of 5 by Creative Research Systems survey software. Ethical approval was obtained from the Committee for the Authorization of Departmental Research (CARD) of the University of Rome "Foro Italico" (case CAR 2018/19).

The study meets the ethical standards of the journal (14).

\section{Survey monkey}

We used the online survey cloud-based software "SurveyMonkey" (Palo Alto, California, USA, www.surveymonkey.com), that is a software commonly used in cross-sectional studies.

All questionnaires were anonymous and voluntary. The Survey was released in November 2018 and remained open for twelve weeks. If the survey link was accessed, it contained an opening message relaying the survey's intent, privacy policy, and investigator details. Skip logic was programmed into the survey so that respondents did not have to answer not applicable questions. Because of this, not all respondents received every question. Ten minutes was the expected time calculated by SurveyMonkey to complete the survey. The software does not permit a double access.

For the extraction data, answers were reported on an Excel file for the Statistician, who was not aware of participants' IP address. No randomization was used.

\section{Questionnaire}

The questionnaire was made up by 28 question based on the standardized Nordic questionnaires that have been developed and validated in order to study the prevalence of occupational musculoskeletal symptoms (13). It has been vali- 
Table I. Questions regarding LBP and its characteristics.

The time frame of prevalence of LBP* (in life, the last year, the last 6 months, the last three months, the last month).

The site of low back pain.

The duration of symptoms.

The frequency of symptoms.

The severity of low back pain measured by NRS***

Secondary disabilities and/or limitation in participation (limitation of ADL $* * * *$ and suspension from training).

Consultation with Health Care Professionals (physician, physical therapist, osteopath).

The use of drugs to control low back pain.

$\mathrm{LBP}^{*}=$ low back pain; $\mathrm{NRS} * *$ numeric rating scale; $\mathrm{ADL}^{* * * *}=$ daily living activity.

dated in Italian and used in a previous study among Italian athletes population $(15,16)$.

The LBP prevalence was defined according to the recommendations for standardized definitions of LBP in prevalence studies (17).

Questions regarding LBP and its characteristics are reported in table $\mathbf{I}$.

A two-sided anatomical drawing was included in the form to identify the back-pain localization.

The severity of LBP was measured by the 11-point (0-10) Numeric rating scale (NRS).

Moreover, additional questions were asked in order to evaluate the correlation between LBP and athletic training other than equestrian sport, the athletes' opinion about LBP in equestrian sports, the impact of LBP on athletes' performance.

The form included also demographic questions about age, gender, height, weight, career duration (number of years of competition in the relevant sport), weekly training volume (hours) and presence of known musculoskeletal disorders (scoliosis, previous fractures, valgus/varus knees), discipline practiced, sport license to ride. A Pain Self Efficacy Questionnaire were also proposed to athletes with CLBP (17).

\section{Low back pain}

LBP is defined as pain and discomfort, localized below the costal margin and above the inferior gluteal folds, with or without referred leg pain. We classified LBP as chronic if it was present for most of the days in the last 3 months (1).

\section{Self-efficacy}

Pain-related self-efficacy is a person's confidence in his or her ability to minimize the impact of pain on physical and psychological functioning, activities and participation.

\section{Competitive athletes}

Athletes were considered competitive if having sport license as Grade 1 (G1), Grade 2 (G2) or any of B license (B) (18).

\section{Disciplines}

Briefly, show jumping is an equestrian discipline in which a rider's horse is jumped over an array of obstacles. The predominant pace of the horse is the canter. In Dressage, riders use their seat and pressure from knees and reins as communication to control the horse to such an extent that they can perform a set of complex figures in the paces of walk, trot, and canter. Eventing is a combination of Dressage, Cross-country, and Jumping, riders use the same horse for each phase of competition.

Show jumping, dressage and eventing are also called Olympic Disciplines. Endurance is a long-distance competition against the clock. Vaulting is the sport of gymnastics and dance routines performed on horseback and on the longe line. Driving involves a carriage pulled by one to four horses. Reining is a judged event designed to show the athletic ability of a ranch type horse. These are called Non-Olympic Disciplines. All the recreational activities conducted in the country are defined Country Horse Riding.

\section{Weekly training volume}

We identified 6 groups according to the hours of training:

Group 1: 1-2 hours/week.

Group 2: 3-4 hours/week.

Group 3: 5-6 hours/week.

Group 4: 7-12 hours/week.

Group 5: 13-18 hours/week.

Group 6: more than 19 hours/week. 


\section{Statistical analysis}

The mean with standard deviation (SD) was used, while median and $25^{\text {th }}-75^{\text {th }}$ percentile were used for other continuous variables. Count and percentages were reported for categorical factors.

Association between LBP and binary characteristics were investigated with Pearson chi square test. A p-value of 0.05 was considered statistically significant. The univariate impact of baseline characteristics of equestrian athletes on LBP was assessed by means of a univariate and multivariate logistic model. Odds ratio (OR) and 95\% CI were estimated. A p-value of 0.05 was considered statistically significant. Statistical analyses were carried out using software STATA (StataCorp. 2019. Stata Statistical Software: Release 16. College Station, TX: StataCorp LLC.).

\section{RESULTS}

\section{Population}

886 Italian equestrian athletes fulfil the survey. The average time to complete the survey was 3 minutes and 59 seconds. Participant characteristics are presented in table II.

The mean age of the athletes who completed the questionnaire was 33.2 years \pm 13.3 .

Considering years of practice, the median value was 16 (10-25) years while the median weekly hours of training was 5.5 hours (3.5-9).

$35 \%$ of athletes follow a physical training plan for equestrian sport. The prevalence of LBP is reported in table III. The athletes declaring at least one episode of LBP were $812(91.6 \%)$, while 658 athletes $(74.2 \%)$ suffered from

Table II. Descriptive data of the partecipants $(n=886)$.

\begin{tabular}{|c|c|c|c|}
\hline Variables & & & \\
\hline Gender & Women: $78.1 \%$ & Man: $21.9 \%$ & \\
\hline Age (years), mean (SD) & $30.6 \pm 11.9$ & $40.6 \pm 13.8$ & \\
\hline Weight (Kg), mean (SD) & $60.1 \pm 9.3$ & $76.5 \pm 10.7$ & \\
\hline Discipline* & & & $\begin{array}{l}\text { S.J. } 65.01 \% \\
\text { Dr } 15.01 \% \\
\text { Eve } 8.01 \% \\
\text { Co } 3.49 \% \\
\text { Rei } 2.48 \% \\
\text { End } 1.24 \% \\
\text { Vau } 1.02 \% \\
\text { Dri } 0.68 \% \\
\text { Oth } 3.06 \% \\
\end{array}$ \\
\hline WTV (hours), median $\left(25^{\circ}-75^{\circ}\right.$ percentile) & & & $5.5(3.5-9)$ \\
\hline Years of sport practice (years), mean (SD) & & & $18.70 \pm 11.59$ \\
\hline Athletic training & & & $\begin{array}{l}\text { Yes: } 35.35 \% \\
\text { No: } 64.65 \%\end{array}$ \\
\hline Musculoskeletal disorders $(\mathrm{n}=701)^{* * * *}$ & & & $\begin{array}{l}\text { Sco: } 30.24 \% \\
\text { Fract: } 19.40 \% \\
\text { Foot: } 17.12 \% \\
\text { Knee: } 10.13 \% \\
\text { DLL: } 6.13 \% \\
\text { Other: } 52.64 \%\end{array}$ \\
\hline
\end{tabular}

*Discipline: S.J. = Show jumping, Dr = Dressage, Eve = Eventing, Co = Country Horse Riding, Rei = Reining, End = Endurance, Vau = Vaulting, Dri = Driving, Oth $=$ Other. ${ }^{* *}$ Sport License: B, G1, G2 = Competitive, N.C. $=$ Non-Competitive. ${ }^{* * *}$ Musculoskeletal disorders: Sco $=$ Scoliosis, Fract $=$ Previous Fractures, Foot= Flat Foot/Pes Cavus, Knee = Varum/Valgus Knee, DLL= Lower Limb Dismetria WTV = Weekly training volume. 
LBP over the last year and $212(23.9 \%)$ during the last three months.

In figure $\mathbf{1}$ are showed frequency and duration of episodes of LBP.

The mean intensity of pain during the last event was 5.75 \pm 2 on NRS.

Table III shows disorders and remedies among patients with LBP. Particularly, 214 athletes $(26.40 \%)$ suffered physical disability during the last event of LBP. Among the athletes
$(62.80 \%)$ who sought care or treatment, $61.69 \%$ consulted a physical therapist, $44.01 \%$ an osteopath and $36.74 \%$ a medical doctor. Several athletes recurred to more than one specialist and 510 athletes $(62.80 \%)$ used drugs to control LBP.

Table IV reports prevalence of LBP among disciplines. Table $\mathrm{V}$ shows results of univariate and multivariate logistic regression.

Weight is a strong risk factor (O.R. 1.05) for LBP $(\mathrm{p}<0.05)$, while age (O.R. 0.95$)$ is a protective factor $(\mathrm{p}<0.05)$.
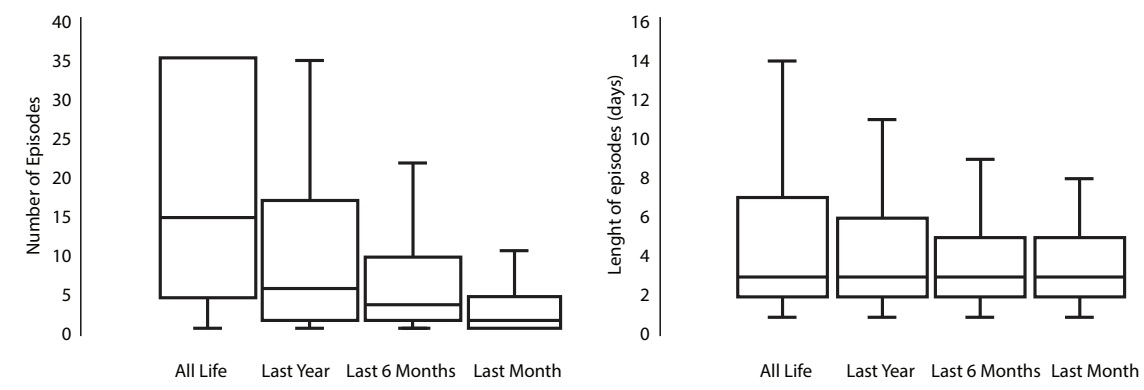

LBP $=$ Low Back Pain

Figure 1. Number and durations of episodes of LBP.

Table III. Prevalence and disorders for athletes with low back pain.

\begin{tabular}{|c|c|}
\hline Prevalence, disorders and remedies & $\mathrm{N}$ (percentage) \\
\hline Lifetime Prevalence & $812(91.6 \%)$ \\
\hline 1 year prevalence & $658(74.2 \%)$ \\
\hline Last month prevalence & $409(46.2 \%)$ \\
\hline CLBP prevalence* & $212(23.9 \%)$ \\
\hline No & $598(73.6 \%)$ \\
\hline Yes & $214(26.4 \%)$ \\
\hline Break of practice & 812 \\
\hline No & $581(71.5 \%)$ \\
\hline Yes & $231(28.5 \%)$ \\
\hline Drugs & 812 \\
\hline No & $510(62.8 \%)$ \\
\hline Yes & $302(37.2 \%)$ \\
\hline
\end{tabular}


Table IV. Results of univariate and multivariate logistic regression.

\begin{tabular}{|c|c|c|c|c|c|c|c|c|}
\hline \multirow{2}{*}{$\begin{array}{l}\text { Disciplines } \\
\text { Showjumping }\end{array}$} & \multirow{2}{*}{$\frac{\mathrm{N}^{*}}{35}$} & \multicolumn{2}{|c|}{ Absence of LBP } & \multicolumn{3}{|c|}{$\mathrm{N}^{*}$ Presence of LBP } & \multirow{2}{*}{$\begin{array}{r}\text { Total } \\
576 \\
\end{array}$} & \multirow{2}{*}{$\begin{array}{l}\text { P-value } \\
\mathrm{P}<0.001\end{array}$} \\
\hline & & $(6.08 \%)$ & [3.95\%] & 541 & $(93.92 \%)$ & {$[61.06 \%]$} & & \\
\hline Dressage & 12 & $(9.02 \%)$ & {$[1.35 \%]$} & 121 & $(90.98 \%)$ & {$[13.65 \%]$} & 133 & $\mathrm{P}<0.001$ \\
\hline Country & 5 & (16.13) & {$[0.56 \%]$} & 26 & $(83.87 \%)$ & {$[2.9 \%]$} & 31 & $\mathrm{P}<0.001$ \\
\hline Reining & 2 & $(9.09 \%)$ & {$[0.22 \%]$} & 20 & $(90.91 \%)$ & {$[2.25 \%]$} & 22 & $\mathrm{P}<0.001$ \\
\hline Vaulting & 0 & $(0 \%)$ & {$[0 \%]$} & 9 & $(100 \%)$ & {$[1.01 \%]$} & 9 & \\
\hline Driving & 1 & $(16.67 \%)$ & {$[0.11 \%]$} & 5 & $(83.33 \%)$ & {$[0.56 \%]$} & 6 & \\
\hline Other & 2 & $(7.41 \%)$ & {$[0.22 \%]$} & 25 & $(92.59 \%)$ & {$[2.82 \%]$} & 27 & \\
\hline Total & 74 & & {$[8.35 \%]$} & 812 & & [91.64\%] & 886 & \\
\hline
\end{tabular}

$* \mathrm{~N}=$ absolute frequencies; in parentheses = percentage on discipline; in bracket = percentage on total of athletes. LBP=Low Back Pain.

Table IV. Prevalence of LBP among disciplines.

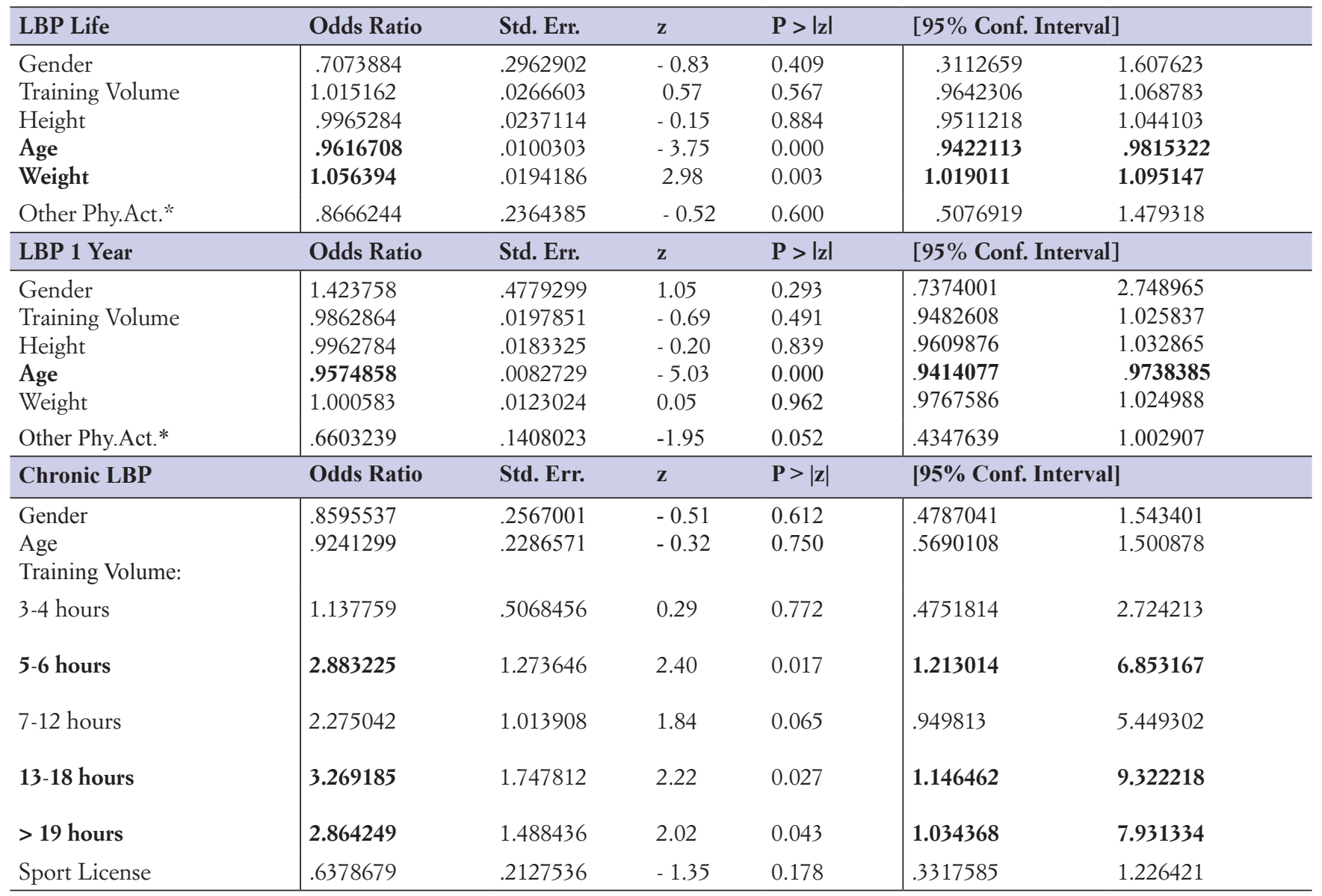

Other physical activities*. 
Gender, hours of training or height were not identified as risk factors for LBP.

Analyzing sport license, competitive and non-competitive athletes did not show a significative association with presence of LBP.

With regard to CLBP, we found a weakly significative association with training volume.

Investigating associated factors, we found that female, such as younger athletes, are more prone to CLBP; nevertheless, associations were not significative $(\mathrm{p}>0.05)$.

Relating to weekly training volume, athletes who ride 5-6 hours (O.R. 2.88), 13-18 hours (O.R. 3.27) or more than 19 hours per week (O.R. 2.86) have a risk to develop CLBP higher than 1-2 hours per week. CLBP is associated with interrupted activity $(\mathrm{p}<0.001)$, drugs consumption $(\mathrm{p}<$ $0.001)$ and restriction in participation $(\mathrm{p}<0.001)$. Moreover, athletes with CLBP believe that LBP has affected their performance and that LBP is a significative condition among equestrian athletes $(\mathrm{p}<0.05)$.

The athletes reporting CLBP over the last three months were asked to complete the Pain Self Efficacy questionnaire (PSE). The mean value of the questionnaire was $37.6 \pm 13.5$. Correlation between NPRS and PSE questionnaire was - 0.28 while Scale reliability coefficient was 0.9458 .

In figure 2 correlations between NPRS and each question of PSE questionnaire are shown.

\section{DISCUSSION}

\section{Low back pain}

The findings of this study clearly show that LBP is very common among Italian equestrian athletes with a life-time and 1 year prevalence of $91.6 \%$ and $74.2 \%$ respectively.

Prevalence of LBP among equestrian athletes appear to be higher than in general population. According with literature $65-80 \%$ and $22-65 \%$ are the life and 1 -year rates for general population, while $24-66 \%$ was the 1 year rates found in athletes $(6,19)$. However, these data come from studies which adopted different definition of LBP and investigated population samples of different age. For this reason, these data should be compared with care.

It is not possible to compare prevalence data between equestrian sport and other sports. This is due to methodological heterogeneity of the studies present in literature, as reported in a systematic review by Trumpeter et al. (6). Compared to previous studies on equestrian athletes, we found higher rates of LBP. These findings should be considered with caution $(9,11)$. Nevertheless, the prevalence of LBP in younger athletes is rising, it remains lower than in adults. Conversely, we found that age is a protective factor against LBP, young athletes are more at risk compared to the older. Our hypothesis is that training sessions of younger athletes are more intense compared to that of older athletes; moreover, older athletes

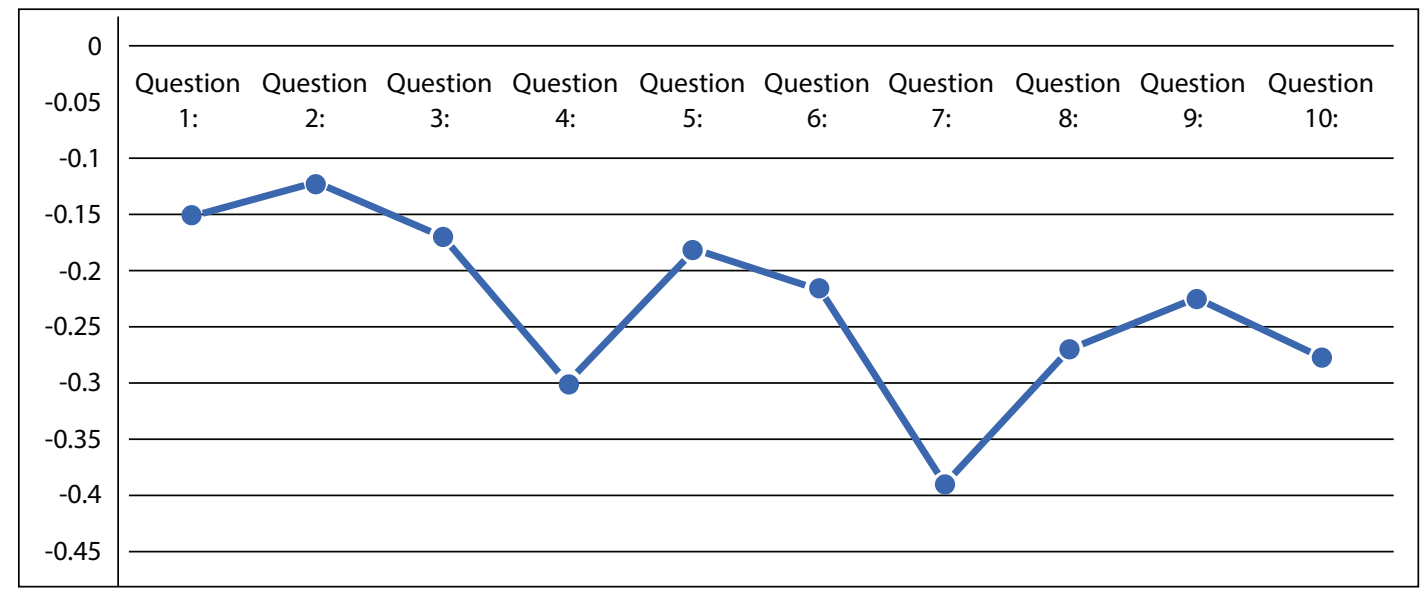

NPRS $=$ Numeric Pain Rating Scale $\quad$ PSE $=$ Pain Self Efficacy

Figure 2. NPRS and PSE questionnaire correlation 
could have a better technical competence compared to younger and that can decrease spinal loads while riding. This hypothesis needs to be confirmed in prospective studies. Male athletes reporting LBP were about $20 \%$ but statistical analysis have not found significant association with gender and this is in agreement with previous study on equestrian sport (9). Investigating disciplines, we found a strong association with LBP: in Show Jumping it appeared to be more frequent (94\% of athletes) compared to other disciplines, while in eventing it was less frequent ( $79 \%$ of athletes). Our results differ from data reported by Kraft et al., but this finding could be explained by the different sample size (9). As found by Kraft et al., we confirm that gender and training volume were not associated with LBP (9). Previous studies found a correlation between weekly training volume and $\operatorname{LBP}(2,5)$. For example, in speed skaters and rowers training volume is a risk factor for back pain. On the other hand other studies on rowers or soccer players did not found this correlation (6). In our study training volume was not found to be related to LBP, this indicate that sport-specific differences might lead to different loads on the spine, but in literature there is not a consensus on this topic (20). As previously reported, training volume, years of sport and practicing other physical activity have not significative association with $\operatorname{LBP}(6,21)$.

The association between weight or Body mass index (BMI) and LBP in general population and in athletes is well known $(21,22)$. It is confirmed that weight is a strong risk factor in equestrian athletes but it was not found a correlation with height or BMI.

\section{Chronic low back pain}

CLBP prevalence was $23.9 \%$, this value is similar compared to $23 \%$ found in general population (1).

Despite CLBP was more frequent in female and younger athletes, we did not find correlation with gender, age, weight, disciplines, or sport license.

Considering weekly training volume, we found that practicing equestrian sport 5-6 hours/week or more has a weak association with CLBP. CLBP might be related to alterations of neuromuscular control as reported by Català et al. but this is only an aspect of the multifactorial etiology of CLBP, comprising psycho-social factors (23).

Analyzing psycho-social aspects, the athletes with CLBP showed more disability in ADL and they tend to suspend sports activity more frequently. Moreover, they habitually use painkillers and non-steroid anti-inflammatory drugs to manage LBP, however it is known, according to international guidelines, that excessive use of drugs does not provide adequate clinical benefit in CLBP (1).

Athletes with CLBP reported limitations in performance, and they believed that LBP is a widespread condition among riders.
To summarize, the impact of psycho-social aspects is distinctly associated with CLBP among equestrian athletes and this is in accordance with Hasenbring et al. (24). The most important aspect considered in CLBP is self-efficacy, notwithstanding, we did not find any correlations between the severity of pain and self-efficacy (25).

\section{Strengths and limits}

This is the first study on the Italian equestrian population and the sample size reached is the largest compared to similar previous study in equestrian sport.

Since it is not possible to have knowledge of how many athletes were aware of the questionnaire, we cannot establish the response rate. We did not analyze by logistic regression some disciplines, considering the little sample size. Additionally, athletes with LBP could have been more likely to fulfil questionnaire; for this reason, responder bias must be taken into consideration.

It should be taken in consideration that a large part of the sample practiced physical training for equestrian sport, and this can lead to a change in the results found.

Granted that this is a cross-sectional study, the results show only correlations and not causations.

\section{CONCLUSIONS}

LBP and CLBP are very common conditions in equestrian athletes and their prevalence is higher compared to general population. LBP is more frequent in show-jumping compared to other disciplines. Age and weight are associated with lifetime LBP, with, respectively, a negative and a positive association. One fourth of Italian riders suffer from CLBP and psycho-social aspects related to CLBP need to be further investigated. Equestrian athletes with CLBP showed more disability in ADLs and tendency to suspend sports more frequently.

Further studies are needed to identify risk factors for LBP and CLBP to realize prevention strategies in equestrian sport.

\section{ACKNOWLEDGEMENTS}

The authors thank the Italian Federation of Equestrian Sport (FISE) for his involvement to collect the data of this project, Andrea White and Claudia Fulgenzi for language assistance.

\section{CONFLICT OF INTERESTS}

The authors declare that they have no conflict of interests. 


\section{REFERENCES}

1. Airaksinen O, Brox JI, Cedraschi C, et al. COST B13 Working Group on Guidelines for Chronic Low Back Pain. Chapter 4. European guidelines for the management of chronic nonspecific low back pain. Eur Spine J 2006;15 Suppl 2:S192-300.

2. Heneweer H, Staes F, Aufdemkampe G, van Rijn M, Vanhees L. Physical activity and low back pain: a systematic review of recent literature. Eur Spine J 2011;20(6):826-45.

3. Shiri R, Falah-Hassani K. Does leisure time physical activity protect against low back pain? Systematic review and meta-analysis of 36 prospective cohort studies. Br J Sports Med 2017;51(19):1410-18.

4. Halonen JI, Shiri R, Magnusson Hanson LL, Lallukka T. Risk and Prognostic Factors of Low Back Pain: Repeated Population-based Cohort Study in Sweden. Spine (Phila Pa 1976) 2019;44(17):1248-55.

5. Fett D, Trompeter K, Platen P. Back pain in elite sports: A cross-sectional study on 1114 athletes. PLoS One 2017;12(6):e0180130.

6. Trompeter K, Fett D, Platen P. Prevalence of Back Pain in Sports: A Systematic Review of the Literature. Sports Med 2017;47(6):1183-207.

7. Mortazavi J, Zebardast J, Mirzashahi B. Low Back Pain in Athletes. Asian J Sports Med 2015;6(2):e24718.

8. Reis FJ, Dias MD, Newlands F, Meziat-Filho N, Macedo AR. Chronic low back pain and disability in Brazilian jiu-jitsu athletes. Phys Ther Sport 2015;16(4):340-3.

9. Kraft CN, Urban N, Ilg A, et al. Influence of the riding discipline and riding intensity on the incidence of back pain in competitive horseback riders. Sportverletz Sportschaden 2007;21(1):29-33.

10. Biau S, Gilbert CH, Gouz J, Roquet CH, Fabis J, Leporcq B. Preliminary study of rider back biomechanics. Comput Methods Biomech Biomed Engin 2013;16 Suppl 1:48-9.

11. Quinn S, Bird S. Influence of saddle type upon the incidence of lower back pain in equestrian riders. Br J Sports Med 1996;30(2):140-4.

12. Kraft CN, Pennekamp PH, Becker U, et al. Magnetic resonance imaging findings of the lumbar spine in elite horseback riders: correlations with back pain, body mass index, trunk/ leg-length coefficient, and riding discipline. Am J Sports Med 2009;37(11):2205-13.

13. Kuorinka I, Jonsson B, Kilbom A, et al. Standardised Nordic questionnaires for the analysis of musculoskeletal symptoms. Appl Ergon 1987;18(3):233-7.
14. Padulo J, Oliva F, Frizziero A, Maffulli N. Muscles, Ligaments and Tendons Journal - Basic principles and recommendations in clinical and field Science Research: 2018 Update. Muscles Ligaments Tendons J 2018;8(3):305-7.

15. Gobba F, Ghersi R, Martinelli S, Richeldi A, Clerici P, Grazioli P. Italian translation and validation of the Nordic IRSST standardized questionnaire for the analysis of musculoskeletal symptoms. Med Lav 2008;99(6):424-43.

16. Maselli F, Ciuro A, Mastrosimone R, et al. Low back pain among Italian rowers: A cross-sectional survey. J Back Musculoskelet Rehabil 2015;28(2):365-76.

17. Nicholas MK. The pain self-efficacy questionnaire: Taking pain into account. Eur J Pain 2007;11(2):153-63.

18. Federazione Italiana Sport Equestri (FISE). Disciplina Delle Autorizzazioni a Montare 2017. Available at: https://www. fise.it/images/Equitazione_di_base/Regolamenti/Disciplina_ Autorizzaz_Montare_delibera_11_06_2018.pdf

19. Urits I, Burshtein A, Sharma M, et al. Low Back Pain, a Comprehensive Review: Pathophysiology, Diagnosis, and Treatment. Curr Pain Headache Rep 2019;23(3):23.

20. Bakker EW, Verhagen AP, van Trijffel E, Lucas C, Koes BW. Spinal mechanical load as a risk factor for low back pain: a systematic review of prospective cohort studies. Spine (Phila Pa 1976) 2009;34(8):281-93.

21. Moradi V, Memari AH, ShayestehFar M, Kordi R. Low Back Pain in Athletes Is Associated with General and Sport Specific Risk Factors: A Comprehensive Review of Longitudinal Studies. Rehabil Res Pract 2015;2015:850184.

22. Zhang TT, Liu Z, Liu YL, Zhao JJ, Liu DW, Tian QB. Obesity as a Risk Factor for Low Back Pain: A Meta-Analysis. Clin Spine Surg 2018;31(1):22-7.

23. Moreno Catala M, Schroll A, Laube G, Arampatzis A. Muscle Strength and Neuromuscular Control in Low-Back Pain: Elite Athletes Versus General Population. Front Neurosci 2018;12:436.

24. Hasenbring MI, Levenig C, Hallner D, et al. Psychosocial risk factors for chronic back pain in the general population and in competitive sports : From theory to clinical screening-a review from the MiSpEx network. Schmerz 2018;32(4):259-73.

25. Chiarotto A, Vanti C, Ostelo RW, et al. The Pain Self-Efficacy Questionnaire: Cross-Cultural Adaptation into Italian and Assessment of Its Measurement Properties. Pain Pract 2015;15(8):738-47. 